\title{
ESTIMATION OF GENETIC VARIABILITY IN SOME COTTON CROSSES (Gossypium barbadense L.) UNDER WATER STRESS.
}

\author{
Abd El-Aty M. S. ${ }^{1}$; H. M. E. Hamoud ${ }^{2}$; A. M. Omar ${ }^{1}$ and \\ H. Sh. Turkey ${ }^{2}$ \\ 1-Agronomy Dept., Fac., of Agric., Kafrelsheikh University. \\ 2- Breeding Dept., Cotton Res., Institute, Agric., Res., Center, Egypt.
}

\begin{abstract}
Water deficit is considered one of the most important factors affecting on cotton yield. The purpose of this study was to assess genotypic variation for water deficit stress in a set of cotton germplasm using geometric mean yield (GMY) and drought suscepatability index $(D S I)$ as a selection criteria and to determine genotype $x$ environment interaction influences on cotton yield. Seven lines and five testers were crossed at Sakha in 2010 growing season. The parents and their 35 crosses were evaluated in two locations Sakha and Elnobaria in growing season 2011 under well waterd (W1) and water limited (W2) regimes in each location. Water stress detrmined by the drought intensity index which was similar in the two locations (0.34 in Elnobaria and 0.32 in sakha).Genotypic variation was detected in the both locations and substintial variation in GMY ranged from 92.3 to $156.2 \mathrm{~g}$ and 54.5 to $135.1 \mathrm{~g}$ for Sakha and Elnobaria, respectively. Significant negative correlation of $D S /$ with seed cotton yield, lint cotton yield, boll weight, seed index and harvest index in the two locations. AMMI analysis showed that interaction principle component (IPCI) effects, and (IPC2) have justified 61.87 and $21.05 \%$ of the total variations related to genotypes interactions in the environments, respectively. Among all the environments, Elnobaria under well waterd (NW1) has been categorized as highly interactive environments, because it exhibited high positive interaction (IPC1 score) effect.
\end{abstract}

\section{INTRODUCTION}

A highly competition between cotton and cereal crops inside Delta region, affected on the dedicated area for cotton crop year by year and subsequently push cotton area to get out step by step outside Delta region to new reclemation areas which, suffering from water shortage. Breeding for yield under stress condition is even more complex due to defficulties to define and apply a precise set of environmental conditions relevant to range of naturally occuring stress scenaries (Levi et al., 2009) . The coparative performance of genotypes under drought stress condition is a common study point in idenfication of drought toterance and selection of genotypes for dry environments. However, High yield potential in the absence of drought (Cattivelli et al., 2008) rather than or as well as, the possession of adaptation specifically favoring performance under drought stres (Fischer and Mourer, 1978, Malik and Wright, 1998). Amongst the abiotic stresses reducing crop productivity, shortag of irrigation water is a primary limiting factor in many regions of the world (Turner, 1997 and Sinculair, 2005). There has been controversy of environment for selection and breeding for yield traits. One approach is to screen germplasm by coducting traits in dry locations to select 
productive genotypes. however, these high yielding genotypes under water stress could likely to be low yielding under well-watered environment (Roosielle and Hamblin, 1981). Other approach suggests testing of germplasm under stress and non-srress conditions and ranking genotypes for drought tolerance succeptibility on reduction of the yield (Blum, 1988).

However, values are confounded with differential yield potential of genotypes, other yield based estimates of drought tolerance are based on geometric mean yield (GMY) (Fernandez, 1993). And drought susceptibility index (DSI) (Fischer and Maurer, 1978). GMY is often used by breeders interested in relevant performance since drought stress may vary in severity regarded to field environment over the locations where $D S I$ is a measure of the reduction in the yield of a genotype under water stress conditions with respect to the mean reduction of all the genotypes under consideration . Genotypic differences in GMY and DSI have been demonstrated in different crop species (Ramirez - Vallego and Kelly, 1998 ; Frahin et al., 2004).

The genetic variation for yield indices including $D S I$ and GMY and their relationship with productivity and physiological attributes in cotton are not well documented. Therefore, the objective of the present study was i) to asses genotypic variation for drought tolerance in a set of germoplasm comprising commercial vareties as well as newly developed elite cotton lines using GMY and $D S I$ as selection criteria and to determine association of these measures with some productivity and physiological attributes ii) to determine the basis of adaptive response for yield in range of enviroments using the AMMI statistical model, Therfore present investigation provides insight into the selection strategies required for identifying superior genotypes for target growing environments. The crosses Suvin $x$ Giza 86, Karshenky $x$ (Giza $75 \times$ sea), Karshenky x(Giza $84 \times$ Giza70 x Giza 51B) X Pima 62), Pima S6 x (Giza 77 x Pima 56), Karshenky x (10229 x Giza 86), Suvin x (10229 x Giza 86) and TNB x (10229 x Giza 86) grouped in quadrant-3 in both locations, which were identified as the most water stress tolerant using both indices as selection criteria.

\section{MATERIALS AND METHODS}

The plant materials used in the present study were obtained by line $\mathrm{x}$ tester crossing. According to this method, five foreign cotton cultivars (Karshenky, Suiven, Pima S6, TNB and Australian 12) were used as the testers with seven Egyptian cotton genotypes, (Giza 86, Giza 92, Giza $75 \times$ Sea, G89 x G86, G 77 x Pima S6, 10229 x Giza 86 and (G84 x G70 x G51B) $X$ Pima 62) as the lines and all these genotypes belong to (Gossypium barbadense L.) at Sakha Agriculture Research Station during 2010 growing season.

47 genotypes (twelve parents and their $F_{1}$ crosses) were evaluated in two locations Sakha and Elnobaria in 2011 growing season. Two irrigation regimes have been used in each location which, furrow irrigation system was used in Sakha with two regimes, well-watered (W1) (eight times) and water limited (W2) (four times). Meanwhile, in Elnobaria, drip irrigation system was 
used, well-watered (W1) (two times every week) and water limited (W2) (one time every week).

Quadruplicated randomized complete block design with one row each of $F_{1}, S$ and their parents which having ten plants with $70 \mathrm{~cm}$ apart, 40 $\mathrm{cm}$ between hills and $4 \mathrm{~m}$ long. Three replications were used for productivity estimates and the $4^{\text {th }}$ for physiological attributes. recommended package of production was followed to raise the crop.

Measurment of productivity traits, Seed cotton yield (SCY) g/plant average six plants gurded for each replication. Lint yield (LY) g/plant, number of bolls (BN) was calculated by dividing seed cotton yield per plant by boll weight, Boll weight calculated as, average of 10 bolls/plant. Seed index (SI), calculated as weight of 100 seed in gram. Plant height $(P H)$ was recorded in centimetres from the first cotyledonary node to the apical bud after 120 days. Harvest index ( $\mathrm{HI})$, was recorded from above ground parts of five plants per plot were harvested at $50 \%$ boll opening and sun-dried in a glasshouse to constant weight before weighing for biological yield (BY) and average per plant for statistical analysis. (HI) Calcalated as the ratio ( $\mathrm{SCY}$ ) to the total above ground (BY) (Ullah et al., 2006 a).

Drought intensity index (D) for each location was calclated as $D=1$ $(X d / X p)$, where $x d$ and $x p$ are mean (SCY) of all genotypes in $\mathrm{W} 2$ and $W 1$ regimes respectively. $\left(Y p^{*} Y d\right)^{1 / 2}$

Geometric mean yield of each genotype was caluclated as $G M Y=$

The formula proposed by (Fisher and Maurer,1978) was used to calculate drought susceptability index $(D S I)$ for each genotype $D S I=(1-(Y d / Y p) / D)$. Where yd and yp are mean yield of a given genotypes in $W 2$ and $W 1$ regime respectively and (D) Drought intensity index.

$\mathrm{K}^{+}$and $\mathrm{Na}^{+}$had estimated in the $4^{\text {th }}$ leaf after 120 days by using Sherwood 410 flame photometer.

$\mathrm{K}^{+}=\{(\mathrm{meg} / \mathrm{l}) / 1000\} \times(50 / 1000) \times(33 / .2) \times 100$, and $\mathrm{Na}^{+}=\{(\mathrm{meg} / \mathrm{l}) / 1000\}$ $\times(50 / 1000) \times(23 / .2) \times 100$ which $\mathrm{K}^{+} \%$ or $\mathrm{Na}^{+} \%=$ meg/l $\times .975$ (Chapman, and pratt. 1961).

To analyze the $G \times E$ interaction, The additive mean and multiplicative interaction (AMMI) model was used. The AMMI stastical model is a combination of customary analysis of variance (ANOVA) and interaction priniciple component analysis (IPCA). The equation of this model is: The AMMI model equation by Gauch (1992) is:

$Y$ ger $-\alpha g-\beta e+\mu=\Sigma n \lambda n y$ gn ỏ en $+\rho$ ge $+\varepsilon$ ger

Where $Y$ ger is the plot of genotype $g$ in the environment e and replicate $r$; $\mu$ is the grand mean; $\alpha g$ is the deviation of the genotype $g$ from the grand mean; $\beta$ e is the deviation of the environment e from the grand mean; $\lambda \mathrm{n}$ is the singular value of PCA axis $n$; $y$ gn is the genotype eigenvector for axis $n$; $o$ en is the environment eigenvector; $\rho$ ge is the residual of the genotype $x$ environment interaction and $\varepsilon$ ger is the error term. 
Abd El-Aty M. S. et al.

\section{RESULTS AND DISCUSSION}

Comparatively larger magnitude for drought intensity index (D) in two locations, Sakha (0.32) and Elnobaria (0.34) which refer to the magnitude of water stress that varied between them, Table 1. Positive association between $\mathrm{Yp}$ and $\mathrm{Yd}$ supported the hypothesis that genotypic advantages selected under near-optimum growing condition may be obtained under less favorable growing environments (Quisenberry et al,1980) However, the correlation was comparatively stronger in Elnobaria ( $r: 0.62)$ under high stress than in Sakha ( $r: 0.47)$. Genotypic variation for $D S I$ and $G M Y$ was tangible in both locations Table 1.In Sakha $D S I$ ranged from 0.27 to 1.49 which twenty five genotypes showed water stress tolerance (DS/ less than one) in comparison with twenty five genotypes in Elnobaria were ranged from 0.23 to 1.74. Meanwhile, twenty two genotypes in Sakha showed less tolerance (DS/ value greats than one) in comparison with twenty two genotypes in Elnobaria. Significant negative association of $D S I$ with seed cotton yield, lint cotton yield, boll weight, seed index and harvest index In the two locations and for number of fruiting branches and plant height in Elnobaria suggested DSI as a useful prediction of drought tolerance in cotton Table 2. Moreover, non significant correlation of $D S I$ with ginning outturn and certain physiological attributes including $\mathrm{Na}^{+}$and $\mathrm{k}^{+}$Table 2 further elucidated which it does not use in identification of water stress tolerant genotypes. Substantial variation in GMY ranged from 92.3 to $156.2 \mathrm{gm}$ and from 54.5 to $135.1 \mathrm{gm}$ was found among the genotypes in Sakha and Elnobaria respectively. The crosses L1xT2, L3xT2, L5XT1, L6xT2, L7xT1, L7xT2 and L7xT3 produced comparatively higher GMY in both locations Table1. Significant positive correlation of GMY was found with seed cotton yield, lint cotton yield and harvest index in both locations under (W2) and boll weight, number of fruiting branches/plant and plant height were also significantly associated with $G M Y$ in Elnobaria under W2 condition, however the level of these association was not significant in Sakha. Significant negative correlation of GMY was found with $\mathrm{K}^{+}$in Sakha and non significant correlation in ELnobaria Table 2.

Significant correlation between $G M Y$ and $Y p(r=0.85)$ in sakha; $(r=0.86)$ in Elnobaria) provides additional support for using GMY as stress tolerance predictor.

$D S I$ and GMY estimates in Sakha and Elnobaria were utilized to generate the bi-plot Figure 1. The genotypes and the crosses were grouped into four quadrants when the bi-plot was truncated at moderate $D S I$ and $G M Y$ in both locations. Quadrant-1 contained cultivars with high DSI and high GMY. The genotypes with high $D S I$ and low $G M Y$ were grouped in quadrant-2.The genotypes characterized with low $D S I$ and high GMY were cluster in quadrant-3 whereas quadrant-4 included cultivars with low DSI and low GMY. 
Table 1: Drought susceptibility index (DSI) and geometric mean yield (GMY) of twelve parents and 35 crosses in Sakha and Elnobaria locations.

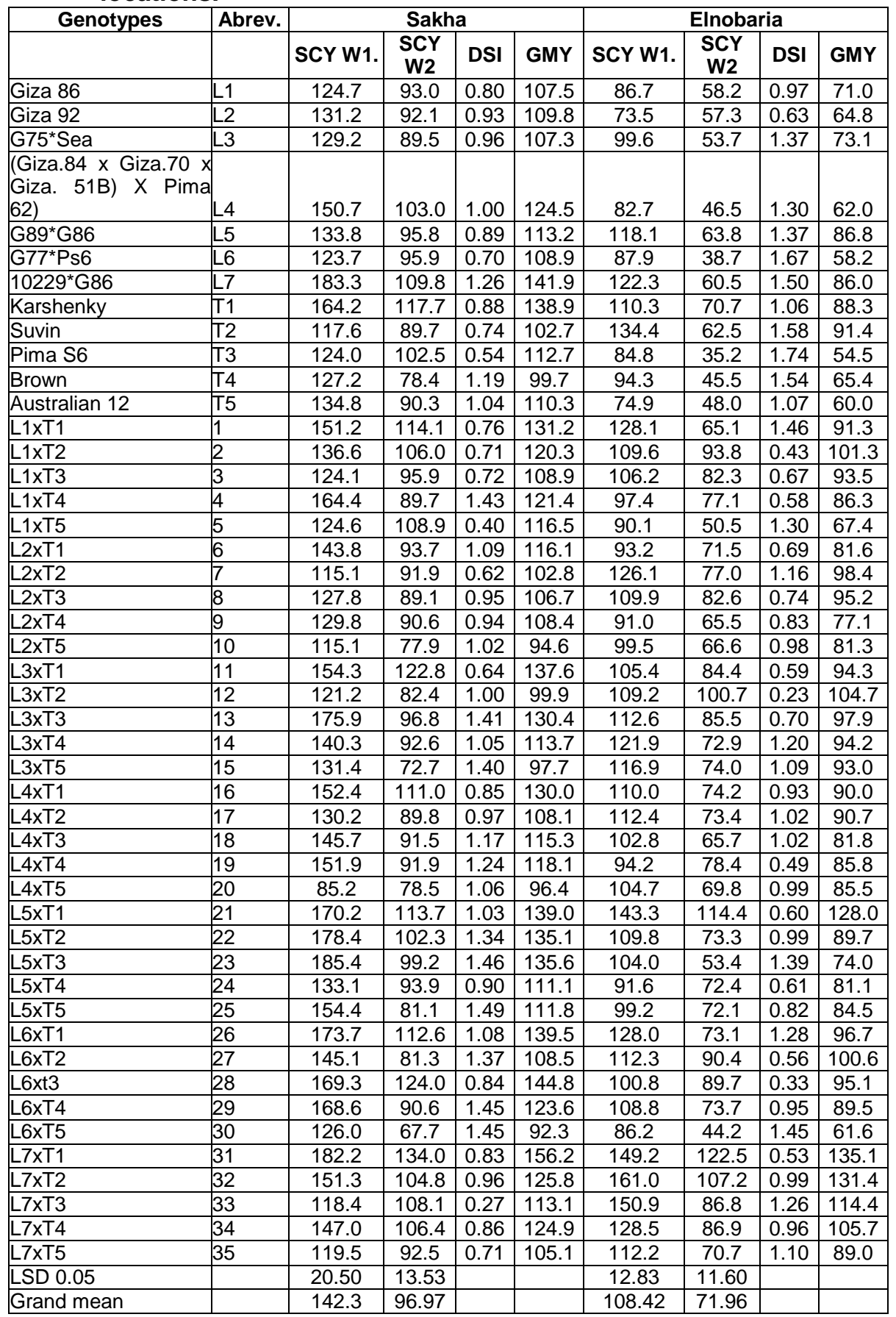


Abd El-Aty M. S. et al.

Table 2.Correlation coefficient between drought susceptibility index, geometric mean with productivity traits of 12 parents and 35 crosses under water stress at Sakha and Elnobaria locations.

\begin{tabular}{|c|c|c|c|c|}
\hline \multirow{2}{*}{ Traits } & \multicolumn{2}{|c|}{ DSI } & \multicolumn{2}{|c|}{ GMY } \\
\hline & Sakha & Elnobaria & Sakha & Elnobaria \\
\hline Seed cotton yield & $-0.54^{\star \star}$ & $-0.71^{\star \star}$ & $0.87^{\star \star}$ & $0.94^{* *}$ \\
\hline Lint cotton yield & $-0.52^{\star *}$ & $-0.65^{\star *}$ & $0.86^{\star *}$ & $0.93^{* *}$ \\
\hline Ginning outturn & $0.01 \mathrm{~ns}$ & $0.10 \mathrm{~ns}$ & $0.10 \mathrm{~ns}$ & $0.09 n s$ \\
\hline Boll weight & $-0.19^{*}$ & $-0.35^{\star \star}$ & $0.15 \mathrm{~ns}$ & $0.42^{\star *}$ \\
\hline Number of fruiting branches & $-0.05 n s$ & $-0.25^{* *}$ & $0.13 \mathrm{~ns}$ & $0.19^{*}$ \\
\hline Plant height & $-0.03 n s$ & $-0.25^{\star \star}$ & $0.14 \mathrm{~ns}$ & $0.20^{*}$ \\
\hline Seed index & $-0.16^{*}$ & $-0.24^{\star *}$ & $-0.03 n s$ & $-0.08 n s$ \\
\hline $\mathrm{k}+$ & $0.02 n s$ & $0.15 n s$ & $-0.21^{\star \star}$ & $0.15 n s$ \\
\hline $\mathrm{Na}+$ & $0.08 n s$ & $-0.02 n s$ & $-0.03 n s$ & $-0.02 n s$ \\
\hline Harvest index & $-0.18^{\star}$ & $-0.37^{\star \star}$ & $0.30^{\star *}$ & $0.49^{\star \star}$ \\
\hline
\end{tabular}

*, significant at $0.05 \%$, ${ }^{\star *}$, highly significant at $0.01 \%$ probability and $\mathrm{ns}$, means non significant.

Drought susceptibility index $(D S I)=(1-\mathrm{Yd} / \mathrm{Yp}) /(1-\mathrm{Xd} / \mathrm{Xp})$. Geometric mean yield $(G M Y)=$ $=\left(Y^{*} Y p\right)^{1 / 2}$.

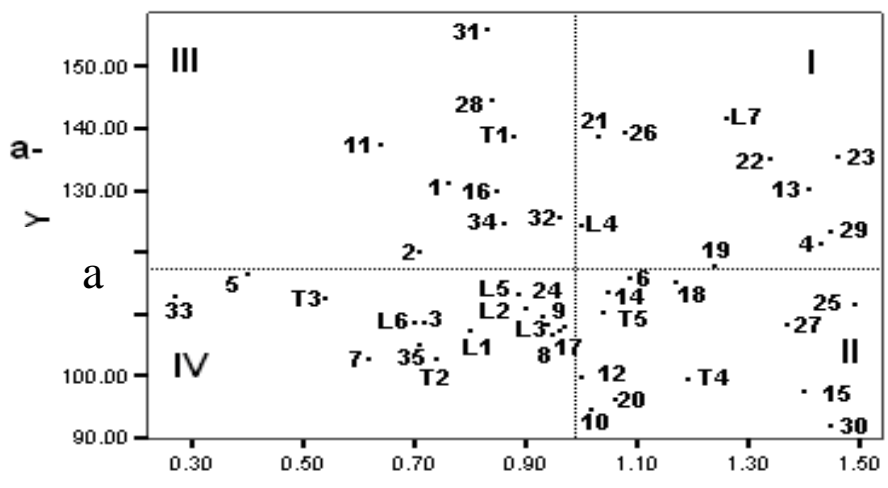

DSI

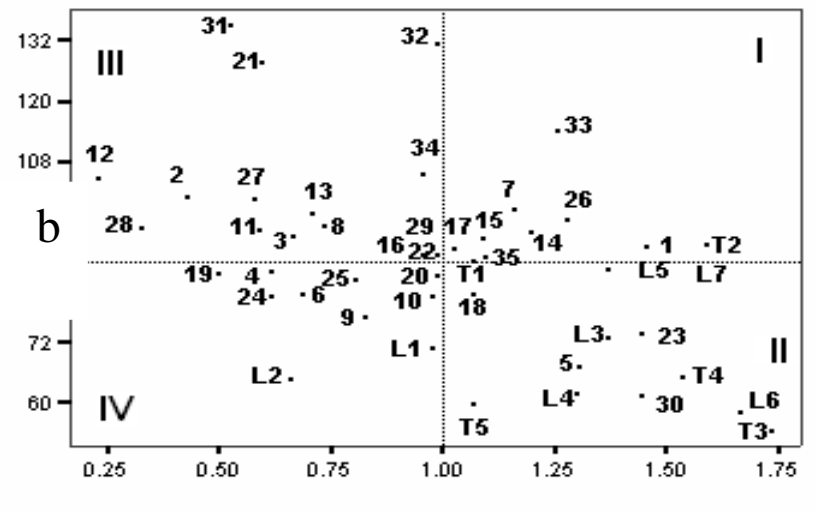

DSI

Fig 1. Biplot between drought susceptibility index (DSI) and geometric mean yield (GMY) for 12 parents and 35 crosses for Sakha (a) and Elnobaria (b) . 
Nine genotypes in Sakha and fifteen genotypes in Elnobaria were placed in quadrant-3. The crosses Suvin x Giza 86, Karshenky x (Giza 75 x sea), Karshenky x(Giza 84 x Giza 70 x Giza 51B) X Pima 62), Pima S6 x (Giza 77 x Pima 56), Karshenky x (10229 x Giza 86), Suvin x (10229 x Giza 86) and TNB $\times(10229 \times$ Giza 86$)$ grouped in quadrant-3 in both locations, which were identified as the most water stress tolerant using both indices as selection criteria. The results indicated that estimation of $D S I$ and GMY supported the hypothesis that selection for combination of $D S I$ and GMY indices might be more useful in improving drought tolerance in cotton instead of using a single yield basis criterion, (Ullah et al., 2006 b).

Stability analysis for seed cotton yield.

The combined ANOVA showed significant genotype, environment and genotype by environmental differences in the data, accounting for $19.31 \%$, $65.09 \%$ and $15.09 \%$ of the total variation respectively Table 3 . The results from AMMI analysis showed that IPC1 and IPC2 were meaningful in probability level of $0.01 \%$. Models of IPC1 and IPC2 have justified 61,87 and $21.05 \%$ of the total variations related to genotypes interactions in the environments, respectively. Hamoud (2008) which reported that E, G and GxE explained $80.28 \%, 7.5 \%$ and $12 \%$ for seed cotton yield, respectively and also, Hamoud et al. (2012) found that AMMI1 and AMMI2 for seed cotton yield was account $51.6 \%$ and $32.23 \%$, respectively. The IPC1 and IPC2 were used in decision making about stability of genotypes and drawing of biplots. Figure 2 showed mean and interaction principle component (IPCI) effects, which lines and testers represents by higher case, crosses represented by lower case as numbers mainwhile, environments represents by NW1 (Elnobaria) well-watered drip irrigations, NW2 (Elnobaria, limited watered drip irrigation), SW1 (Sakha, well-watered) and SW2 (Sakha, limited watered).

Table 3. AMMI analysis of variance for cotton yield

\begin{tabular}{|l|c|c|c|c|}
\hline \multicolumn{1}{|c|}{ SOURCE } & D.F. & S.S. & M.S. & SS\% \\
\hline Genotypes & 46 & 35690 & $775.569^{\star *}$ & 19.31 \\
\hline Environments & 3 & 120262 & $40087.3^{\star *}$ & 65.09 \\
\hline Genotypes X Environments & 138 & 28806.9 & $208.745^{\star *}$ & 15.59 \\
\hline AMMI COMPONENT 1 (IPC1) & 48 & 17824.8 & $371.351^{\star *}$ & 61.87 \\
\hline AMMI COMPONENT 2 (IPC2) & 46 & 6066.34 & $131.87^{\star *}$ & 21.05 \\
\hline AMMI COMPONENT 3 (IPC3) & 44 & 4915.69 & 111.72 & 17.06 \\
\hline Total & 187 & 184759 & & \\
\hline
\end{tabular}

**, Significant at $0.01 \%$ probability.

Whatever, these spots are near zero or origin of coordinates, they have little interactions and if their yield is high, then they would be more stable and spots which are further from the origin of coordinates are unstable, accordingly, the testers, 1,3 and 5 and the line 2 in addition the crosses 9, 3, $17,2,29,13,26,1,4$ and 28 were near zero or origin of coordinates, so that, they placed on group of genotypes which have a good stability. The abscissa showed the main effects and the ordinate showed the frist multiplicative axis term (IPC1). The horizontal line showed the interaction score of zero and the vertical line indicated the grand mean yield. The crosses 27, 34, 21, 24, 19, 
Abd El-Aty M. S. et al.

25, 11 and the lines 5 and 6 were further the origin of coordinates and they are unstable.

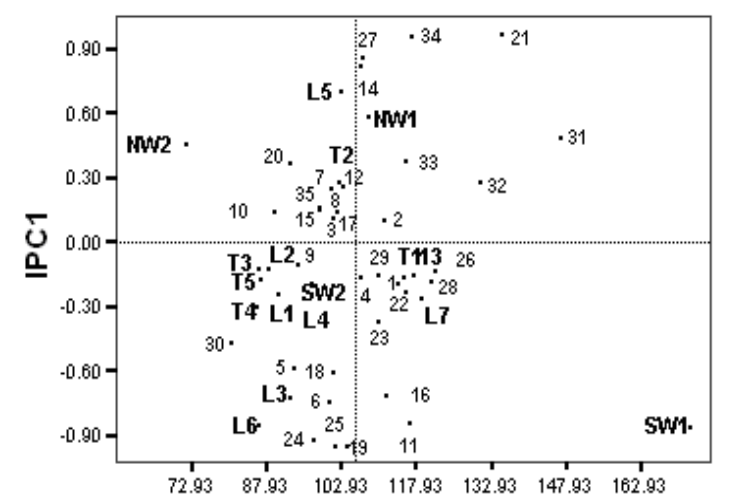

Mean SCY

Figrie 2. AMMI b iplot showing the main and interaction (IPC1) effects of both genotypes and environments on seed cotton yield, AMMI additive main effects and multị licative interaction; PCprinc iple components anslysis axis.

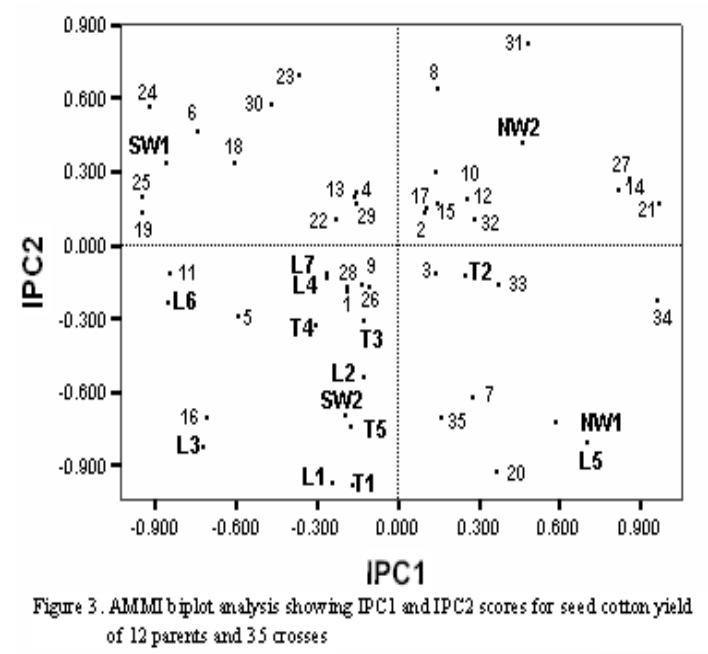

For Figure 3, and related to model AMMI 12, in which environments and genotypes are displayed in bi plots. The crosses, 31, 8, 24, 25, 19, 20, 34, 27, 14 and 21 were more far away from the origin of coordinates and based on this model they are recognized as unstable genotypes, in addition the lines 3, 1, 6 and plus the testers, 1 and 5 also were far away from the origin. In contrast, the crosses 9, 28, 3, 2, 17, 29, 22 and the lines 7 and 4 plus the tester 2 were located near to origin points of coordinates and they have general compatibility relation to the most regions. Among all the environments, NW1 has been categorized as highly interactive environments, because it exhibited high positive interaction (IPC1 score) effect. Separation between NW1 and NW2 and each of SW1 and SW2 might have been due to substantial differences in total water supply received during the crop growth. 


\section{CONCLUSION}

The analysis have shown the insight into the nature of $G X E$ interaction in the cotton raised under water stress and emphasises importance of varietal development for this condition. Furthermore this study brings out that, drought tolerance in cotton is related to $D S I$ and $G M Y$ for more efficient selection to acquire higher yield under drought condition. Bi-plots generates by AMMI model gives more variable and hidden useful information from the data, which give over an overall picture of genotypes behavior under moisture stress condition. The crosses 2, $28,26,13$ and 29 came out as drought tolerant crosses and revealed stability tolerance across environments and could be exploited in breeding program aiming to improve drought tolerance.

\section{REFERENCES}

Blum, A. (1988). Plant breeding for stress environments. CRC press, Florida. Crop Sci.,21:43-47.

Cattivelli, L., F. Rizza, F.W. Badeck, E.mazzucotelli,A.M. Mastranglo, E. Francia, C. Mare,A. Tondelli and A.M Stanca, (2008). Drought tolerance improvement in crop plants:An intergrated view from breeding to genomics. Field crop Res., 105:1-4.

Champman, H. D and Pratt( 1961 ). Methods of analysis of soil,plant and water . Univ. Calf.

Fernandez, G.C.J. (1993). Effective selection criteria for assessing plant stress tolerance. In:Adaption of food crops to temperature and water stress, C.G. Kuo (ed.). AVRDC, Shanhua, Taiwan, pp:257-270.

Fischer, R.A. and R. Maurer. (1978). Drought resistance in spring wheat cultivars. 1. Grain yield responses. Aust. J. Agic. Res., 29:897-912.

Frahin, M. A., J. C. Rosas, N. Mayek Perez, E. Lopez-salinas, J.A. AcostaCallegos and J.D Kelly. (2004). Breeding beans for resistance to terminal droght in the lowland tropics. Euphytica, 136:223-232.

Gauch, H. G. (1992). Statistical analysis of regional yield traits AMMI analysis of factorial designs . Elsevier, Amsterdam.

Hamoud, H. M. E (2008). Studies on Genotype x Environment Interaction using GGE-Biplot Analysis for seed Cotton Yield in Delta region (Egypt). Egypt. J. Agric. Res. Vol, 86. No, 6. P, 2351-2364.

Hamoud, H.M.E; Abd El-Bary A.M.R., Yehia, W.M.B and Soliman Y.A. (2012). Application of AMMI Model and GGE biplot analysis of multienvironments trials data in Egyptian cotton. $1^{\text {st }}$ Alex. International Cotton Conf. from 17-18 April.

Levi, A. A. H. Palerson, V. Barak, D. Yakir, B. Wang, P. W. Chee and Y. Saranga, (2009). Field evaluation of cotton near-isogenic lines introgressed with QTLs for productivity and drought related traits. MOL. Bread., 23:179-195.

Malik, T. A. H. and D. Wright, (1998). Morphological traits and breeding for drought resistance in wheat. JAPS, 8: 93-99. 
Quisenberry, J.E., B. Roark, D.W. Fryer and R.J Kohel. (1980). Effectiveness of selection in upland cotton in stress environments. Crop Sci., 20:450453.

Rameriz- Vallego, P. and I.D. Kelly. (1998). Traits related to drought resistance in common bean. Euphytica, 99:127. 139.

Roosielle, A.A. and J. Hamblin, (1981). Theoretical aspects for yield in stress and non-stress environments. Crop Sci., 21: 943-946.

Sinculair, T.R. (2005) Theoretical analysis of soil and plant traits influencing daily plant water flux on drying soils .Agron.J,97: 1148-1152.

Turner,N,C, (1997). Further progress in crop water relations. Adv. Agron., 58:293-338.

Ullah, I. M. Rahman, M. Ashraf and Y. Zafar (2006 a). Genotypic variation for drought tolerance in cotton (Gossypium hirsutum L.): Leaf gas exchange and productivity. (NIBGE), P.O. Box 577, Pakistan.

Ullah, I. M, UR, Rahman and Y, Zafar(2006 b). Genotypic variation for drought tolerance in cotton (Gossypium hirsutum L.):seed cotton yield responses. Pak. J. Bot., 38(5):1679-1687.

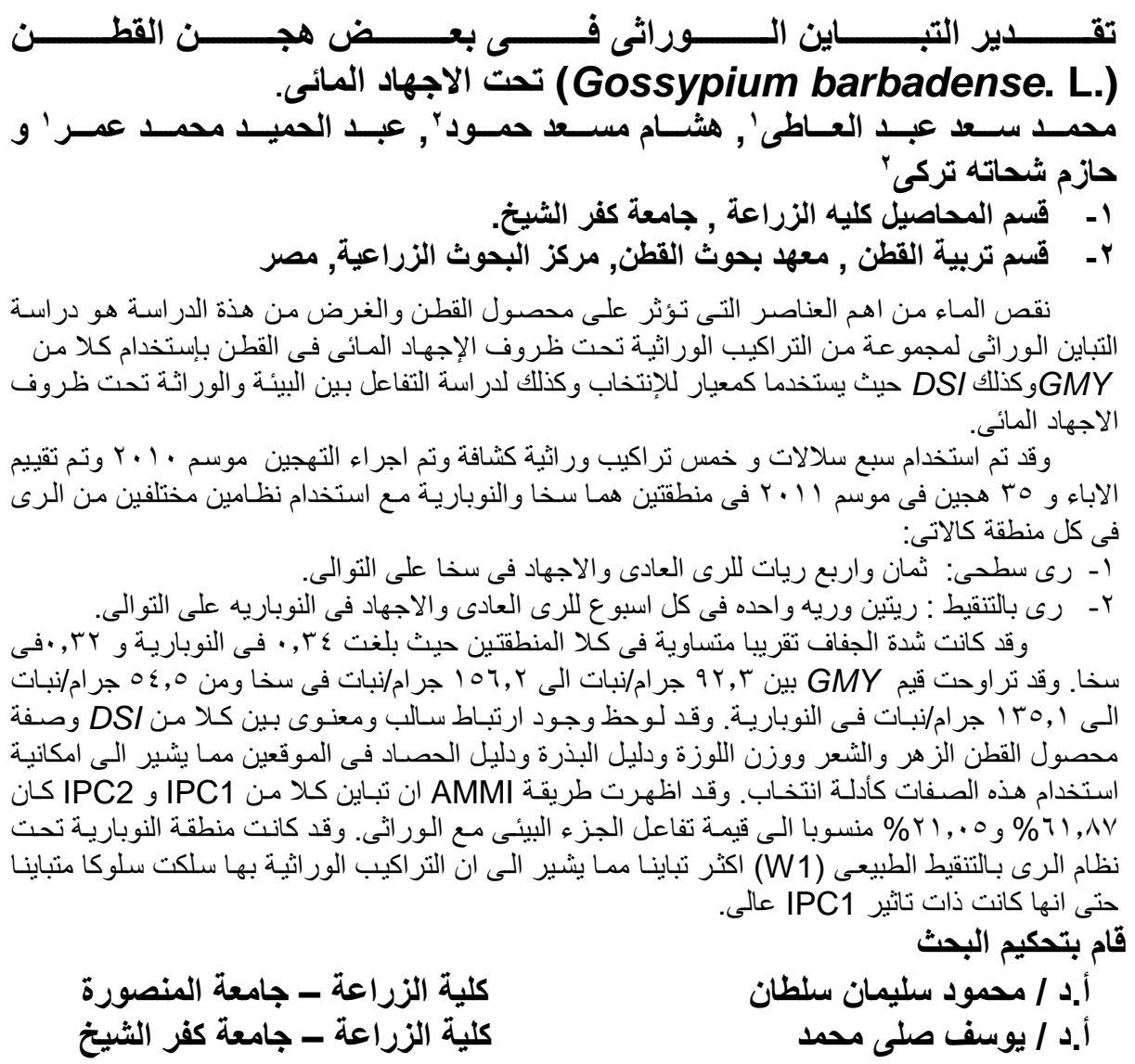

